\title{
Incidence of Zika Virus Disease by Age and Sex - Puerto Rico, November 1, 2015-October 20, 2016
}

\author{
Matthew Lozier, $\mathrm{PhD}^{1}$; Laura Adams, DVM ${ }^{1}$; Mitchelle Flores Febo, MS²,2; Jomil Torres-Aponte, MS²; Melissa Bello-Pagan, MS²; Kyle R. Ryff, MPH²; \\ Jorge Munoz-Jordan, $\mathrm{PhD}^{1}$; Myriam Garcia ${ }^{3,4}$; Aidsa Rivera, MS ${ }^{1}$; Jennifer S. Read, MD ${ }^{1}$; Stephen H. Waterman, MD ${ }^{1}$; Tyler M. Sharp, PhD ${ }^{1}$; \\ Brenda Rivera-Garcia, DVM²
}

Zika virus is a flavivirus transmitted primarily by Aedes species mosquitoes; symptoms of infection include rash, arthralgia, fever, and conjunctivitis. ${ }^{*} \dagger$ Zika virus infection during pregnancy can cause microcephaly and other serious brain anomalies (1), and in rare cases, Zika virus infection has been associated with Guillain-Barré syndrome (2) and severe thrombocytopenia (3). This report describes the incidence of reported symptomatic Zika virus disease in the U.S. territory of Puerto Rico by age and sex. During November 1, 2015-October 20, 2016, 62,500 suspected Zika virus disease cases were reported to the Puerto Rico Department of Health (PRDH); 29,345 (47\%) were confirmed by reverse transcription-polymerase chain reaction (RT-PCR) testing, or were presumptively diagnosed based on serological testing. The highest incidence among confirmed or presumptive cases occurred among persons aged 20-29 years (1,150 cases per 100,000 residents). Among 28,219 (96.2\%) nonpregnant patients with confirmed or presumptive Zika virus disease, incidence was higher among women (936 per 100,000 population) than men (576 per $100,000)$ for all age groups $\geq 20$ years, and the majority $(61 \%)$ of reported Zika virus disease cases occurred in females. Among suspected Zika virus disease cases in nonpregnant adults aged $\geq 40$ years, the percentage that tested positive among females $(52 \%)$ was higher than that among males $(47 \%)(\mathrm{p}<0.01)$. Reasons for the higher incidence of Zika virus disease among women aged $\geq 20$ years are not known; serosurveys of persons living near confirmed Zika virus disease cases might help to elucidate these findings. Residents of and travelers to Puerto Rico should remove or cover standing water, practice mosquito abatement, employ mosquito bite avoidance behaviors, take precautions to reduce the risk for sexual transmission, and seek medical care for any acute illness with rash or fever.

Epidemiologic surveillance for Zika virus disease in Puerto Rico includes completion of the arboviral case investigation form that records demographic data and symptoms, ${ }^{\mathbb{}}$ and submission of clinical specimens for diagnostic testing of all persons with one or more signs or symptoms compatible with Zika virus disease for evidence of Zika, dengue, and

\footnotetext{
${ }^{*}$ http://www.cdc.gov/zika.

$\dagger^{\dagger}$ http://www.salud.gov.pr/Sobre-tu-Salud/Pages/Condiciones/Zika.aspx.

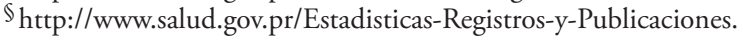

chikungunya virus infection, using the Trioplex RT-PCR or immunoglobulin $\mathrm{M}$ (IgM) capture enzyme-linked immunosorbent assay (MAC-ELISA) ${ }^{* *}$ tests (4). A suspected case of Zika virus disease is defined as a symptomatic illness with at least one arboviral disease-like symptom (e.g., rash, arthralgia, or fever) in a patient seen at a health care facility, from whom a clinical specimen was collected, and which was reported to $\mathrm{PRDH}$. A presumptive case is defined as a positive Zika virus result by MAC-ELISA and a negative dengue virus IgM ELISA. A confirmed case of Zika virus disease is defined as a positive RT-PCR result for Zika virus from a suspected case. Puerto Rico population estimates from 2015 were used to calculate incidence of Zika virus disease. ${ }^{\dagger \dagger}$

During November 1, 2015-October 20, 2016, specimens from 62,500 patients with suspected Zika virus disease were evaluated by RT-PCR and/or MAC-ELISA; 28,341 (45\%) were confirmed and 1,004 (2\%) presumptive cases were identified. Among confirmed and presumptive Zika virus disease cases, 1,117 (4\%) were in pregnant women. Among all confirmed and presumptive Zika virus disease cases, the median age was 32 years (range $=16$ days -100 years) and $18,384(63 \%)$ were female.

The overall estimated incidence of confirmed and presumptive Zika virus disease was 844 cases per 100,000 residents. The highest incidences were in persons aged 20-29 years (1,150 cases per 100,000 residents), and $10-19$ years (1,111 per 100,000) (Figure 1) when pregnant women were included. When Zika virus-infected pregnant women, who might be more likely to seek health care and be tested for suspected Zika virus disease than women in the general population, were excluded, incidence of Zika virus disease among all persons was 812 per 100,000; 17,267 (61\%) of persons with confirmed or presumptive Zika virus disease were female. Incidence among males and nonpregnant females aged 1-9 years was 795 per 100,000, and increased with age, peaking at 1,073 per 100,000 among persons aged $10-19$ years. Among males, the

\footnotetext{
Ittp://www.fda.gov/downloads/MedicalDevices/Safety/EmergencySituations/ UCM491592.pdf.

** http://www.fda.gov/downloads/MedicalDevices/Safety/EmergencySituations/ UCM488044.pdf.

${ }^{\dagger \dagger}$ http://factfinder.census.gov/faces/tableservices/jsf/pages/productview. xhtml?src=CF.
} 


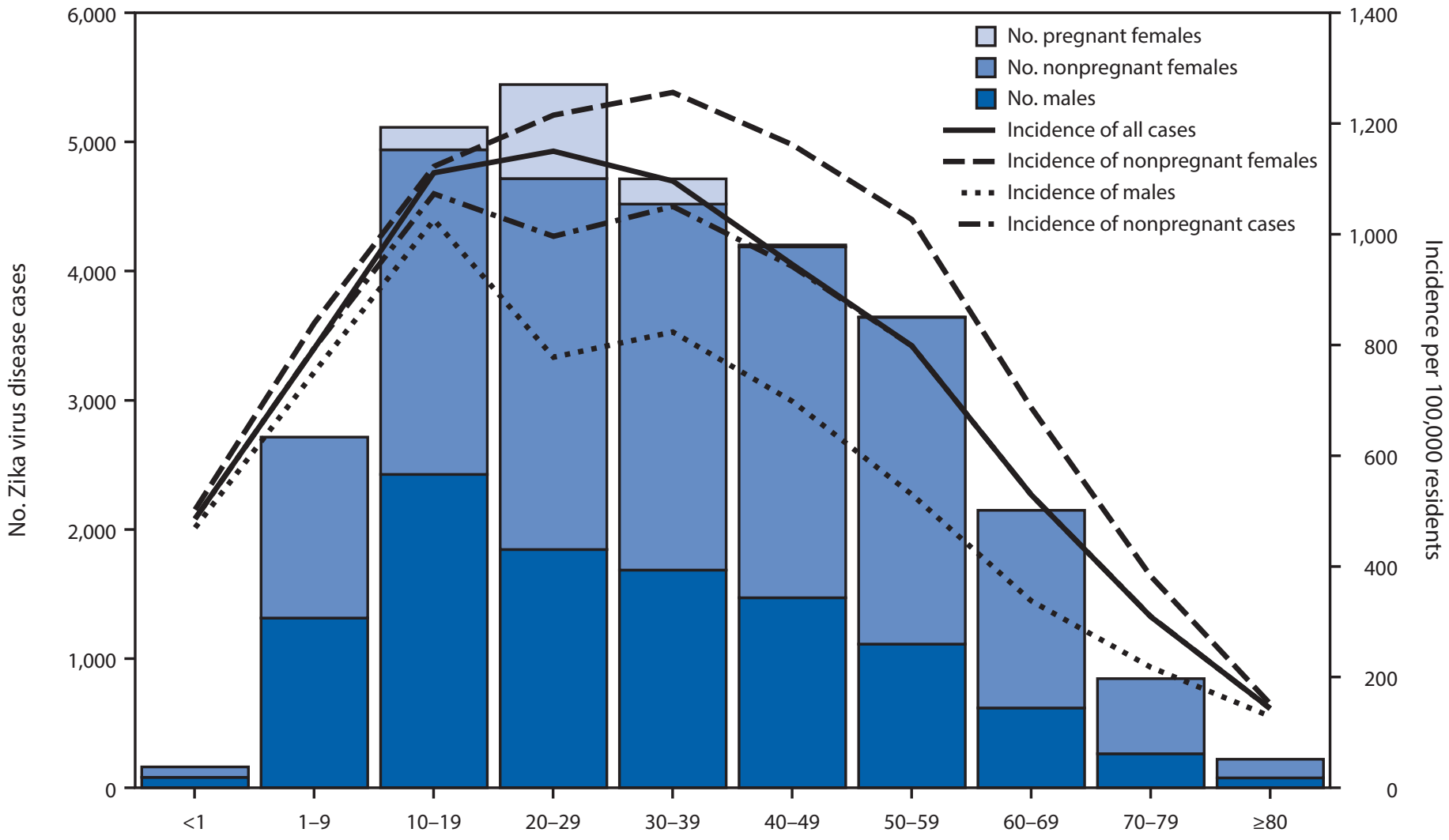

Age groups (yrs)

* Sex was not reported for 9 cases; age or date of birth was not reported for 125 cases.

highest incidence was in persons aged 10-19 years (1,026 per $100,000)$ and declined as age increased. Although incidence in nonpregnant females aged 10-19 (1,123 per 100,000) was similar to that in males of the same age, incidence in females continued to increase with age and peaked among women aged 30-39 years (1,256 per 100,000). Incidence decreased among women in older age groups, but remained well above the incidence for males (Figure 1).

Among all cases of Zika virus disease in nonpregnant persons, $61 \%$ were in females; in all age groups females accounted for the majority of cases. The proportion of female Zika virus disease cases was significantly higher than the proportion of females in the general population in Puerto Rico for all age groups except infants and persons aged $\geq 80$ years.

To account for potential differences in who sought medical care and reporting of a suspected case, the percentage of suspected Zika virus disease cases among nonpregnant persons that tested positive for Zika virus infection was compared by sex and age group. Among suspected cases reported to PRDH, the proportion of cases in males and females who tested positive was not significantly different among infants and persons aged
10-39 years (Figure 2). However, the proportion of suspected cases in persons who tested positive was significantly higher among females than males aged $1-9$ years and $\geq 40$ years. Among suspected cases in persons aged $\geq 40$ years, the largest difference in the proportion of persons testing positive for Zika virus disease between females and males was among persons aged 60-69 years; in this age group, among suspected cases, $51 \%$ of females and $42 \%$ of males tested positive $(\mathrm{p}<0.001)$.

\section{Discussion}

Puerto Rico's database of Zika virus disease cases includes the largest number of laboratory-confirmed cases in the world. The findings of the age and sex distribution of Zika virus disease cases in Puerto Rico reported in this analysis are consistent with patterns observed among suspected cases in other countries, and notably, differs from the patterns observed during previous outbreaks of other arbovirus diseases in Puerto Rico. Whereas cases of dengue in 2010 (5) and chikungunya in 2014 (6) were approximately equally distributed among men and women in Puerto Rico, more than 60\% of nonpregnant Zika virus disease cases occurred in women. This disparity was most 
FIGURE 2. Number of reported suspected Zika virus disease cases among males and nonpregnant females, and percent that tested positive for Zika virus by age group and sex $(n=57,727)^{*}$ — Puerto Rico, November 1, 2015-October 20, 2016

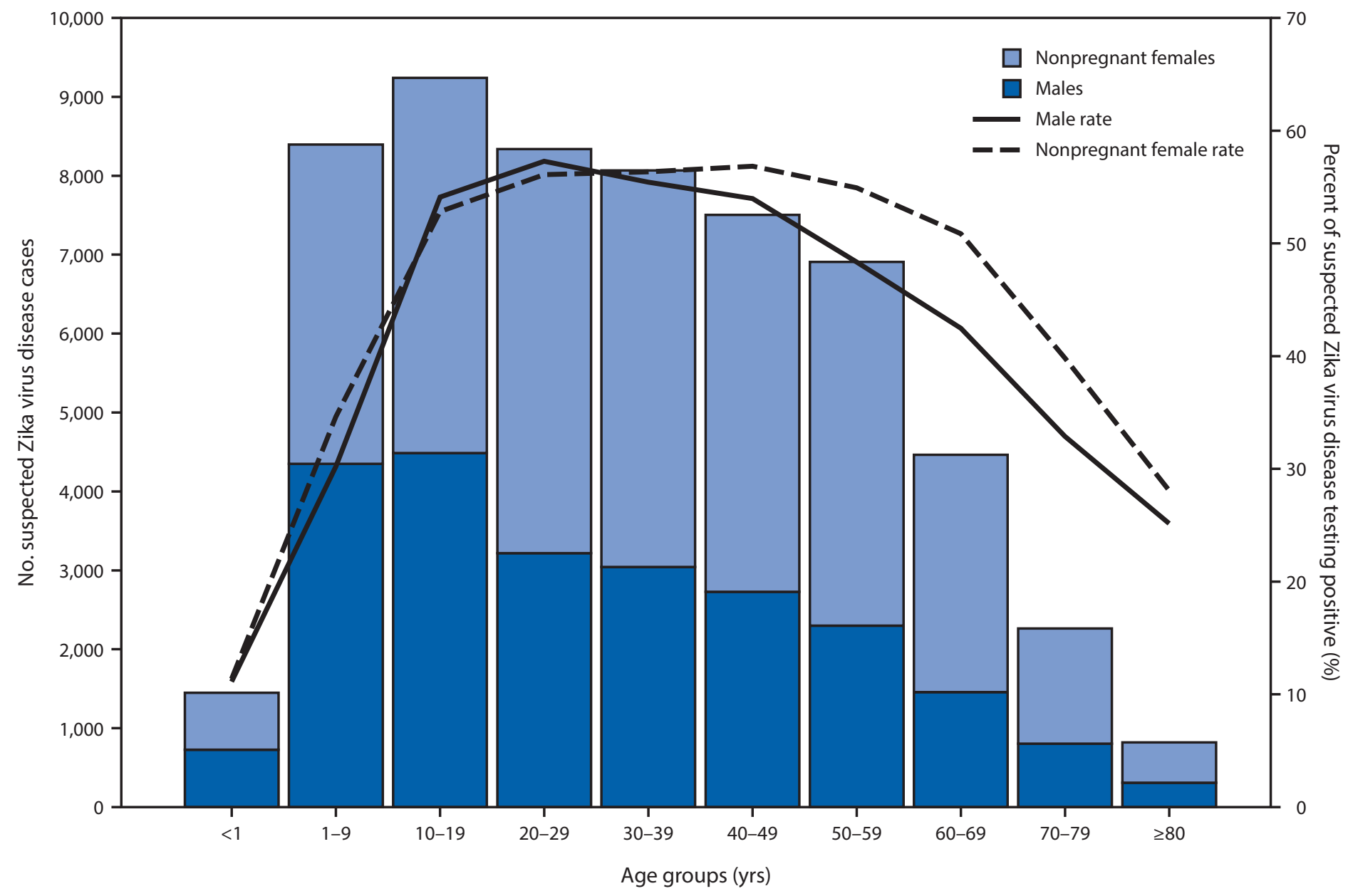

* Sex was not reported for 33 cases; age or date of birth was not reported for 251 cases.

prominent among women aged $\geq 20$ years. In addition, among suspected cases, a higher proportion of females aged $\geq 40$ years tested positive for Zika virus infection than did males of the same age. It is not known why Zika virus disease incidence is higher among women aged $\geq 20$ years.

Similar observations have been made in Bahia state (Brazil) and El Salvador, where, overall, the reported incidence of clinically suspected Zika virus disease cases was $75 \%$ higher in females than in males (7). In addition, rates of probable Zika virus disease cases in Bahia state and El Salvador were highest in women aged 20-49 years (7), the same age group most highly affected in Puerto Rico. During the 2007 Zika virus disease outbreak in Yap State, Micronesia, the attack rate among confirmed cases was highest among persons aged 30-39 years, and the overall attack rate for persons seeking care was higher among women than among men (8). Similar to Puerto Rico, $61 \%$ of confirmed or probable Zika virus infections in Yap occurred among females (8). The skewing of the distribution of Zika virus disease cases toward women in Brazil was postulated to be because of more exposure to Aedes mosquitoes in the home, more severe symptoms among women in certain age groups, differences in health care-seeking behavior, reporting biases by health care workers, and sexual transmission $(7,9)$. Although male-to-female and female-to-male (10) sexual transmission has been documented, data from Rio de Janeiro suggest that differences in infection rates between men and women might be explained by male-to-female sexual transmission (9). The same explanations might be responsible for the observed trends in Puerto Rico. The relative contribution of sexual transmission of Zika virus to rates of Zika virus disease is only beginning to be explored, including relative risk of developing disease in men and women, and through sexual transmission versus mosquito-borne transmission.

Potential explanations for the higher reported incidence of Zika virus disease in nonpregnant women than men aged $\geq 20$ years include possible differences in the rates of infection, 


\section{Summary}

What is already known about this topic?

Zika virus has been circulating in Puerto Rico since November 2015. Previous reports from Brazil and El Salvador have demonstrated higher rates of infection in females, and suggested that Zika virus disease incidence is higher among persons aged $20-49$ years.

What is added by this report?

Among 28,219 nonpregnant persons with laboratory evidence of Zika virus disease identified in Puerto Rico during November 1, 2015-October 20, 2016, incidence was highest among women aged $20-49$ years. Women aged $40-79$ years with suspected cases were more likely to test positive for Zika virus infection than those in males in the same age group.

What are the implications for public health practice?

Serosurveys are needed to identify the rates of Zika virus infection among males and females of all ages in Puerto Rico to determine whether observed differential disease rates reflects differential rates of infection, development of disease, or seeking medical care. Accurate information on disease burden will enable identification of populations most affected to target health messaging and interventions. Residents of and travelers to Puerto Rico should remove or cover standing water, employ mosquito bite avoidance behaviors, take precautions to reduce the risk for sexual transmission, and seek medical care for any acute illness with rash or fever.

differences in who sought care following symptomatic infection, and susceptibility to development of disease after infection. These differences might be explained by conducting serosurveys to estimate the rate of Zika virus infection among all age groups, and associating the relative frequencies by which infected persons report symptoms, seek medical care, and are reported as suspected cases. CDC and PRDH are currently conducting serosurveys among persons living near confirmed Zika virus disease cases to help answer these questions.

The findings of this report are subject to at least three limitations. First, incidence rates could be skewed by health careseeking bias, because women are more likely to seek medical care. $\$ \mathbb{S}$ Second, women of childbearing age might have been more likely to seek care because a Zika virus infection during pregnancy can cause microcephaly and other serious brain anomalies. In an effort to remove these biases, the percentage of suspected Zika virus disease cases among nonpregnant persons that tested positive for Zika virus infection were calculated and found to be higher among women than among men. Finally, underreporting of suspected Zika virus disease cases to PRDH could result in these data not accurately reflecting the actual distribution of Zika virus disease in Puerto Rico.

\footnotetext{
$\overline{\$ \$ ~ h t t p: / / j i d . o x f o r d j o u r n a l s . o r g / c o n t e n t / 210 / 4 / 535 . f u l l . p d f+h t m l . ~}$
}

This investigation revealed that Zika virus infections occur in males and females in all age groups in Puerto Rico. To reduce the risk for infection, all residents of and travelers to Puerto Rico should remove or cover standing water and employ mosquito bite avoidance behaviors, including using mosquito repellents, wearing long-sleeved shirts and pants, and ensure that homes are properly enclosed (e.g., screening windows and doors, closing windows, and using air conditioning). To reduce the risk for sexual transmission, especially to pregnant women, sexual partners who reside in or traveled to Puerto Rico should abstain from sex, or use condoms consistently and correctly each time they have sex. 99 Women and their partners who want to delay or avoid pregnancy in the context of the Zika outbreak should work with a health care provider to find a birth control method that is safe and effective. ${ }^{* * *}$ Such measures can also help avoid unintended pregnancies and reduce the risk for congenitally acquired Zika virus infection. Clinicians who suspect Zika virus disease in patients who reside in or have recently returned from areas with ongoing Zika virus transmission should work with their state and local health authorities to test patients for Zika virus infection. Additional information is available at http://www.cdc.gov/zika/index.html.

\footnotetext{
$99 \mathrm{http} / / /$ www.cdc.gov/zika/prevention/protect-yourself-during-sex.html.

${ }^{* * *}$ http://www.cdc.gov/zika/pregnancy/women-and-their-partners.html.
}

${ }^{1}$ Division of Vector-Borne Diseases, National Center for Emerging and Zoonotic
Infectious Diseases, CDC; ${ }^{2}$ Office of Epidemiology and Research, Puerto Rico
Department of Health; ${ }^{3}$ Biological and Chemical Emergencies Laboratory,
Office of Public Health Preparedness and Response, Puerto Rico Department
of Health; ${ }^{4}$ Public Health Laboratory, Puerto Rico Department of Health.
Corresponding author: Matthew Lozier, mlozier@cdc.gov, 787-706-2264.

\section{References}

1. Rasmussen SA, Jamieson DJ, Honein MA, Petersen LR. Zika virus and birth defects-reviewing the evidence for causality. N Engl J Med 2016;374:1981-7. http://dx.doi.org/10.1056/NEJMsr1604338

2. Cao-Lormeau VM, Blake A, Mons S, et al. Guillain-Barré Syndrome outbreak associated with Zika virus infection in French Polynesia: a case-control study. Lancet 2016;387:1531-9. http://dx.doi.org/10.1016/ S0140-6736(16)00562-6

3. Sharp TM, Muñoz-Jordán J, Perez-Padilla J, et al. Zika virus infection associated with severe thrombocytopenia. Clin Infect Dis 2016;63:1198-201.

4. Adams L, Bello-Pagan M, Lozier M, et al. Update: ongoing Zika virus transmission-Puerto Rico, November 1, 2015-July 7, 2016. MMWR Morb Mortal Wkly Rep 2016;65:774-9. http://dx.doi.org/10.15585/ mmwr.mm6530e1

5. Sharp TM, Hunsperger E, Santiago GA, et al. Virus-specific differences in rates of disease during the 2010 Dengue epidemic in Puerto Rico. PLoS Negl Trop Dis 2013;7:e2159. http://dx.doi.org/10.1371/journal.pntd.0002159

6. Sharp TM, Roth NM, Torres J, et al. Chikungunya cases identified through passive surveillance and household investigations-Puerto Rico, May 5August 12, 2014. MMWR Morb Mortal Wkly Rep 2014;63:1121-8.

7. dos Santos T, Rodriguez A, Almiron M, et al. Zika virus and the GuillainBarré Syndrome-case series from seven countries. N Engl J Med 2016;375:1598-601. http://dx.doi.org/10.1056/NEJMc1609015 
8. Duffy MR, Chen TH, Hancock WT, et al. Zika virus outbreak on Yap Island, Federated States of Micronesia. N Engl J Med 2009;360:2536-43. http://dx.doi.org/10.1056/NEJMoa0805715

9. Coelho FC, Durovni B, Saraceni V, et al. Higher incidence of Zika in adult women than adult men in Rio de Janeiro suggests a significant contribution of sexual transmission from men to women. Int J Infect Dis 2016;51:128-32. http://dx.doi.org/10.1016/j.ijid.2016.08.023
10. Davidson A, Slavinski S, Komoto K, Rakeman J, Weiss D. Suspected female-to-male sexual transmission of Zika virus-New York City, 2016. MMWR Morb Mortal Wkly Rep 2016;65:716-7. http://dx.doi. org/10.15585/mmwr.mm6528e2 